Scheherazade C. Ibrahim, MD

Charlotte M. Chiong, MD $1,2,3$

Nathaniel W. Yang, MD 1,2,4

'Department of Otorhinolaryngology

Philippine General Hospital

University of the Philippines Manila

${ }^{2}$ Philippine National Ear Institute

National Institutes of Health

University of the Philippines Manila

${ }^{3}$ Department of Otorhinolaryngology

Manila Doctors Hospital

${ }^{4}$ Department of Otolaryngology Head and Neck Surgery The Medical City Hospital
Correspondence: Scheherazade C. Ibrahim, MD Ibrahim ENT Medical Clinic

Corner Mabini and SK Pendatun Sts.

Cotabato City 9600

Philippines

Phone: (064) 4215388

Email: sche_ibrahim@yahoo.com

No funding support was received for this study. The authors signed a disclosure that they have no proprietary or financial interest with any organization that may have a direct interest in the subject matter of this manuscript, or in any product used or cited in this article.

Presented at the Descriptive Research Contest, Philippine Society of Otolaryngology-Head and Neck Surgery, Jade Valley Restaurant, Quezon City, Philippines, September 25, 2008; the $1^{\text {st }}$ AANOA Congress ( 1 st Place), Dusit Thani, Makati City, Philippines on November 28, 2008 and $10^{\text {th }}$ Asia Pacific Congress on Deafness, Landmark Hotel, Bangkok, Thailand on August 6, 2009.

\section{Superior Semicircular Canal Dehiscence Syndrome: Review of Clinical Manifestations in Adults and Children}

\begin{abstract}
Objective: This report aims to determine the clinical manifestations and management of patients with superior semicircular canal dehiscence syndrome (SSCDS).

Methods:

Design: Case series

Setting: Tertiary hospitals and private clinics

Participants: Out of 30 patients with vestibular vertigo or otologic symptoms, 14 patients were diagnosed with SSCDS based on high resolution computed tomographic scan (HRCT). The demographic features, incidence of specific signs and symptoms and management of these patients were described, including the audiograms, vestibular evoked myogenic potential (VEMP) responses and ancillary tests.
\end{abstract}

Results: Vertigo was the most common vestibular symptom of SSCDS. Tullio phenomenon was elicited in $50 \%$ of patients with confirmed dehiscence on HRCT scan. Low frequency $(250 \mathrm{~Hz}$ and $500 \mathrm{~Hz}$ ) air-bone gap was noted in $21.4 \%$ of patients. Lowered VEMP responses were also noted in $66.7 \%$ of patients with confirmed SSCDS. Severity of symptoms may determine its management.

Conclusion: The diagnosis of SSCDS does not conform to a specific clinical presentation or audiologic result and good clinical correlation is needed in order to raise suspicion of the disease and prompt the clinician to order confirmatory imaging by computed tomographic scan or magnetic resonance imaging. The presence of this syndrome in a proportion of children that is greater than previously reported needs further study as these children may be genetically predisposed to have thinned out superior semicircular canals that eventually become dehisced albeit at an earlier age.

Key words: Superior semicircular canal dehiscence, pure tone audiometry, vestibular evoked myogenic potential 


\section{Superior semicircular canal dehiscence syndrome (SSCDS)} is a pathologic condition with vestibular symptoms provoked or exacerbated by sound or pressure stimuli due to the absence of the bony layer covering the superior semicircular canal. This is a recently recognized disease entity that most clinicians may overlook in diagnosing patients presenting with vertigo or nystagmus as some patients may present only with hearing loss and no associated vestibular symptoms. SSCDS has sparked a lot of interest over the past years leading to research aimed at understanding this abnormality and emphasizing its importance as a cause of intractable vertigo.

In 1998, Minor et al. reported eight patients with vertigo, oscillopsia or disequilibrium related to sound, changes in middle ear pressure or changes in intracranial pressure.' They also had vertical-torsional eye movements induced by sound and/or pressure stimuli. High-resolution computed tomographic (HRCT) scan of the temporal bone confirmed the presence of a dehiscent superior semicircular canal among these patients. In the Philippines, the first case of SSCDS in an 80-year-old patient was reported in 2003 by Ong and Chiong from the Manila Doctors Hospital. ${ }^{2}$ Smullen et al. reported the presence of incapacitating vertigo in three patients who were confirmed radiologically to have dehiscent superior semicircular canals. ${ }^{3}$

In a series of 13 patients by Modugno et al., ${ }^{4}$ vestibular-evoked myogenic potential (VEMP) alterations in response to stimuli of abnormally low intensity has led to the suspicion of the presence of the third window effect. The vestibular dysfunction is linked to the principle of the Tullio phenomenon such that there is an abnormal stimulation of the posterior labyrinth due to sound or mechanical pressure. ${ }^{5}$

SSCDS can mimic other otologic entities. The associated vestibular symptoms have been demonstrated in other pathologies such as congenital deafness, ${ }^{4}$ Meniere's disease, ${ }_{1}^{6}$ perilymph fistula, head trauma, ${ }^{8}$ Lyme disease ${ }^{9}$ and cholesteatoma with semicircular canal erosion and fenestration. ${ }^{10}$ Some patients may present simply with either a sudden hearing loss ${ }^{11}$ or a conductive hearing loss thus being subjected to surgery such as stapedectomy before being accurately diagnosed. ${ }^{12}$ Given the scanty literature on how patients with SSCDS may manifest, the diagnosis and management of this disease remains a challenge to clinicians. This report aims to describe Filipino SSCDS patients according to their clinical presentation and diagnostic test results in order to underline the importance of weighing the clinical evidence for a presumptive diagnosis of SSCDS and choose the proper management for patients with this disease.

\section{METHODS}

Patients suspected to have the clinical manifestations of SSCDS within the period of 1994-2008 were retrospectively identified. Criteria for inclusion were patients with positive dehiscence confirmed on HRCT scan or magnetic resonance imaging (MRI) of the temporal bone and the presence of at least one of the following: (1) vestibular or auditory symptoms evoked by sound or pressure stimuli, (2) lowered VEMP threshold/ enlarged amplitude and (3) presence of air-bone gap at low frequencies on audiometry.

The clinical records, audiogram, VEMP responses, CT or MRI scans as well as other ancillary test results were reviewed to assess the different clinical manifestations and diagnostic results that may indicate the presence of this syndrome. VEMP testing was performed with a Neuropack MEB 2200 and Silver (Ag) electrodes (Nihon Kohden, Tokyo, Japan) using similar parameters as described by other studies. The vestibulocollic reflex was evoked by rarefactive clicks delivered to the ear by calibrated headphones (Nihon Kohden, Tokyo, Japan) at 0.1 millisecond duration, stimulation rate of $7 \mathrm{~Hz}$ and an intensity of $105 \mathrm{~dB}$ normal hearing level down to threshold. The signal was band passfiltered from $20 \mathrm{~Hz}$ to $3 \mathrm{kHz}$. A total of 100 sweeps were averaged and the responses were reproduced in a second turn. Because the VEMP equipment was not working for a certain period during the time of this review, the test could not be performed on all patients.

\section{RESULTS}

Certain cases are presented to emphasize different circumstances wherein superior semicircular canal dehiscence syndrome may occur. The rest of the results of this study are summarized in Tables 1 to 5 .

\section{Case Report 1 (Patient 1)}

A 30-year-old female complained of vertigo induced by loud sounds. It was so severe that it affected her daily activities such as doing household chores. There were no other associated symptoms or otologic diseases. A temporal bone HRCT scan confirmed the presence of a dehiscence on the right superior semicircular canal. There was absence of repeatable wave peaks on the right on VEMP testing. Audiometry showed low frequency air-bone gap on the involved side. There were also abnormal saccades and smooth pursuit tests. Her vertigo was so debilitating that it prompted her to undergo resurfacing combined with plugging of the dehiscent superior semicircular canal through the middle cranial fossa approach. She claimed marked improvement after 


\section{ORIGINAL ARTICLES}

surgery. Post-operative audiometry showed closure of previous low frequency air-bone gap. She has remained symptom free for 18 months post-operatively.

\section{Case Report 2 (Patient 4)}

A 34-year-old male first complained of disequilibrium characterized as a feeling of swaying which later on progressed to recurrent vertigo. This was aggravated by exposure to loud sounds. The patient also presented with gaze-evoked tinnitus. Examination elicited Tullio phenomenon and Hennebert's sign (nystagmus on application of pressure on the external auditory canal). Audiometry showed normal hearing acuity in both ears. At this time (1994), he was being managed as an atypical case of Meniere's disease and was put on diuretics for almost four years with relief of symptoms. As the signs and symptoms were recurrent and with the advent of studies introducing the SSCDS in 1998, a CT scan of the temporal bone was obtained when the patient followed up in 2005 confirming the presence of a dehiscent superior semicircular canal. This patient is presently being managed medically with good control of symptoms.

\section{Case Report 3 (Patient 14)}

A 4-year-old female was brought to the clinic by her parents for complaints of vertigo and vomiting. From the time she was a few months old, her mother noted occasional vomiting not associated with feeding, fever or abdominal pain. The patient would also suddenly close her eyes at times. As she grew up, she preferred tilting her head towards her right. Electroencephalography as well as cranial ultrasound revealed normal results. It wasn't until she was able to talk that she described what she was feeling, saying that her surroundings were "umiikot-ikot," (rotating). CT scan of the temporal bone confirmed a dehiscent superior semicircular canal on the right. There was a low VEMP threshold response on the right. Electronystagmography (ENG) revealed abnormal saccades and smooth pursuit tests. Audiometry showed normal hearing acuity on both ears. Currently, the patient's symptoms are controlled through medical management.

\section{Descriptive Analysis}

Thirty patients who were initially diagnosed with SSCDS were between 2 to 79 years old with a mean age of $38.7 \pm 21.8$ (median age= $37.5)$. There were 24 adult patients $(80 \%)$ and 6 pediatric patients $(20 \%)$. Seventeen out of the 30 patients were male (56.7\%) and 13 out of the 30 were female (43.3\%). Patients consulted with different presenting symptoms, vertigo being the most common, followed by hearing loss, tinnitus and disequilibrium. Only two patients were found to have concomitant sinusitis.

Patients were grouped according to those with confirmed SSCDS on HRCT scan (Table 1), those patients whose CT scans were not available for review but were first reported to have SSCDS from chart records (Table 2) and those without dehiscent superior semicircular canal on HRCT scan (Table 3).

The 14 patients with confirmed SSCDS had a mean age of $39.8 \pm$ 23.9 (median age $=40)($ Table 1$)$. Eight out of the $14(57.1 \%)$ were female and 6 out of the 14 (42.9\%) were male. Eleven of the 14 patients (78.6\%) were adults and 3 of the 14 patients (21.4\%) were children. Vertigo was the most common presenting symptom ( 9 out of 14 patients $=64.3 \%$ ). The presence of Tullio phenomenon was noted in 7 of the 14 patients (50\%). Only 3 out of the 14 patients (21.4\%) showed an air-bone gap at lower frequencies based on audiometry. VEMP testing was done in only 6 patients and 4 of these 6 patients demonstrated either a lowered VEMP threshold or enlarged amplitude responses (66.7\%). Based on CT scans, a bony defect on the right was observed in $35.7 \%$ patients ( 5 of the 14 patients), $28.6 \%$ on the left (4 of the 14 patients) and $35.7 \%$ on both sides ( 5 of the 14 patients). Only one out of the 14 patients underwent surgical intervention (resurfacing combined with plugging of the dehisced superior semicircular canal).

Only one out of the 14 patients with confirmed SSCDS showed all the classic hallmarks of SSCDS including a vestibular symptom, a positive Tullio phenomenon, an air-bone gap in lower frequencies on audiometry, a lowered VEMP response, abnormal ENG findings and normal tympanogram result. The rest of the adult patients as seen on Table 1 manifested a combination of signs and symptoms. Two out of the three pediatric patients initially presented with hearing loss; in contrast, adult patients usually complained of vertigo.

Some of the 14 patients with confirmed SSCDS underwent other ancillary tests. Six patients had an ENG which all showed abnormal saccade and smooth pursuit results as well as caloric weakness in one out of the six patients (16.67\%). Only 5 out of the 14 patients had tympanometry which all yielded Type A tympanograms.

Ten patients were initially reported to a have a dehiscent superior semicircular canal but their CT scans were not available for review (Table 2). These patients presented with disequilibrium, hearing loss, tinnitus and vertigo. A positive Tullio phenomenon was elicited in 3 of the 10 patients (30\%). On audiometry, 4 of the 10 patients (40\%) showed an air-bone gap on lower frequencies. Three out of the 5 patients (60\%) who underwent VEMP testing had either a lowered VEMP threshold or enlarged amplitude responses. ENG was done in four of the patients showing abnormal results while tympanometry was done in three patients with normal results. 
There were six patients who were considered to have SSCDS but were proven otherwise on review of their HRCT scans (Table 3). None of the six patients demonstrated a positive Tullio phenomenon. Three of the six patients (50\%) presented with tinnitus. Four out of the 6 patients (66.7\%) had an air-bone gap at lower frequencies. The three patients who underwent VEMP testing showed normal VEMP threshold and amplitude responses. All three of those who underwent ENG elicited abnormal responses. Three of those who underwent tympanometry showed normal results except for one patient with a possible middle ear problem (Type B tympanogram).

Table 4 summarizes the clinical findings among those with confirmed SSCDS versus those confirmed to be without SSCDS and those with presumptive diagnosis of SSCDS. Tullio phenomenon was observed in $50 \%$ (7 out of the 14 patients) of confirmed SSCDS cases, but none among those confirmed without SSCDS based on HRCT scan. Lowfrequency air-bone gap was found in more than $20 \%$ of SSCDS patients (3 out of the 14 patients) and a positive VEMP response in $67 \%$ (4 out of 6 patients); this is in sharp contrast to $67 \%$ of those without SSCDS who have low-frequency air-bone gap (4 out of 6 patients) and negative VEMP response ( 3 out of 3 patients). The proportion of patients with Tullio phenomenon, air-bone gap and VEMP response among those with presumptive diagnosis of SSCDS but whose imaging results were not reviewed may mean that this group comprises a mixture of patients with and without SSCDS.

\section{DISCUSSION}

A diagnosis of SSCDS does not conform to a specific clinical presentation, thus good clinical correlation of the patient's manifestations and test results is needed to increase the index of suspicion for SSCDS, which must be confirmed by radiologic imaging.

The characterization of superior semicircular canal dehiscence syndrome as a disease entity has just been recently explored. Minor et al. in 2005 studied 60 patients who manifested with vestibular symptoms and showed a dehisced superior semicircular canal on imaging. ${ }^{13}$ This disorder seems to have no predilection for laterality or gender. It is not confined to a certain age group. It usually occurs in adults but can also be present in children as seen in this study, lending support to the possibility of a congenitally thinned out superior semicircular canal that may dehisce at a very early age with minor increases in intracranial pressure.

The vestibular symptom of vertigo is the most common clinical manifestation of this disorder which may be induced by sound or pressure stimuli. Adults seemed to complain of this symptom more than children. In this series, 2 out of 3 children with confirmed SSCDS had more prominent hearing loss than vestibular symptoms, and this may have been due to their inability to adequately express what they were experiencing. Instead, these patients demonstrated thenunexplainable behavior such as persistent head tilting and frequent closing of the eyes as shown by the youngest patient we presented (Case Report 3). This vestibular symptom may be attributed to the "third mobile window effect" into the inner ear. ${ }^{14}$ The first two windows being referred to are the round and oval windows and the third window refers to the dehisced superior semicircular canal. Any stimulus that may induce an inward pressure at the round and oval windows (i.e. Valsalva maneuver against pinched nostrils) will result in an inward bulging of the membranous canal of the dehiscence and consequent ampullofugal (excitatory) deflection of the cupula of the semicircular canal. On the other hand, the outward pressure (i.e. Toynbee maneuver) at the round and oval windows will result to an ampullopetal (inhibitory) deflection of the cupula of the semicircular canal.

Vertigo and abnormal eye and/or head movements due to loud sounds were demonstrated in fifty percent of the patients with confirmed SSCDS in contrast to those patients whose HRCT scan showed no dehiscence of the superior semicircular canal. These soundinduced vestibular responses were first reported by Tullio in 1926 when he studied fistulized labyrinths of pigeons. ${ }^{15}$ It is postulated that the dehisced bone in the labyrinth allows a second pathway for sound pressure to be dissipated. The vibration at the oval window induces the perilymph fluid to circulate abnormally within the vestibular apparatus to stimulate the hair cells and thus produce the sensation of vertigo. However, this phenomenon has been demonstrated also in patients with other pathologies. The abnormal sound energy transmission within the vestibular apparatus that may connect to the extraocular muscles also explains this occurrence. This phenomenon is also hypothesized to cause tinnitus which can be a complaint in patients with SSCDS.

Auditory manifestation (i.e. low frequency air-bone gap) refers to an air-bone gap of $10 \mathrm{~dB}$ or greater at 250 to $500 \mathrm{~Hz}$. The air-bone gap was not due to a disorder in the middle ear conductive mechanism because tympanometry revealed Type A tracings among patients with confirmed SSCDS. Middle ear exploration (for those who were not diagnosed primarily with semicircular canal dehiscence) also showed no abnormality. ${ }^{12}$ The "third window mobile effect" may also explain this such that acoustic energy dissipates through the dehiscence. The energy is shunted away from the cochlea resulting in hearing loss by air conduction. ${ }^{12} \mathrm{As}$ a result there is an increased threshold for air-conducted sounds and a reduced threshold for bone-conducted sounds.

HRCT scans of the temporal bone have shown a dehisced or thinned 


\section{ORIGINAL ARTICLES}

Philippine Journal Of Otolaryngology-Head And Neck Surgery

Vol. 24 No. 2 July - DeCEMBER 2009

PJOHSS

Table 1. Patients with SSCDS as confirmed on HRCT Scan

\begin{tabular}{|c|c|c|c|c|c|c|c|c|c|c|c|c|}
\hline Patient & Age & Sex* & Laterality & $\begin{array}{c}\text { Presenting } \\
\text { Symptom }\end{array}$ & $\begin{array}{c}\text { Associated } \\
\text { Symptomst }\end{array}$ & $\begin{array}{c}\text { Tullio } \\
\text { Phenomenon }\end{array}$ & $\begin{array}{c}\text { Low frequency } \\
\text { Air-bone gaptt }\end{array}$ & $\begin{array}{c}\text { VeMP } \\
\text { Response** }\end{array}$ & $\begin{array}{c}\text { ENG*** } \\
\text { Tympano- } \\
\text { metry }\end{array}$ & $\begin{array}{c}\text { History of } \\
\text { Surgery }\end{array}$ \\
\hline 1 & 30 & F & Right & V & HL & $(+)$ & $(+)$ & $(+)$ & AS, ASP & Type A, AU & $(+)$ \\
\hline 2 & 78 & F & Left & V & HL & $(-)$ & $(+)$ & NA & NA & NA & $(-)$ \\
\hline 3 & 40 & F & Bilateral & D & T & $(-)$ & $(-)$ & $(+)$ & NA & NA & $(-)$ \\
\hline 4 & 34 & M & Right & V & T & $(+)$ & $(-)$ & NA & NA & NA & $(-)$ \\
\hline 5 & 57 & M & Bilateral & T & V & $(-)$ & $(-)$ & $(-)$ & AS, ASP & NA & $(-)$ \\
\hline 6 & 60 & M & Bilateral & V & T & $(+)$ & $(-)$ & NA & NA & NA & $(-)$ \\
\hline 7 & 51 & F & Right & V & T & $(+)$ & $(-)$ & NA & NA & NA & $(-)$ \\
\hline 8 & 36 & M & Left & V & T & $(+)$ & $(-)$ & NA & NA & NA & $(-)$ \\
\hline 9 & 40 & M & Bilateral & V & T & $(+)$ & $(-)$ & NA & NA & NA & $(-)$ \\
\hline 10 & 71 & F & Right & V & HL & $(+)$ & $(+)$ & $(-)$ & AS, ASP & Type A, AU & $(-)$ \\
\hline 11 & 49 & M & Left & T & V & $(-)$ & $(-)$ & (+) & AS, ASP & Type A, AU & $(-)$ \\
\hline 12 & 5 & F & Left & HL & None & $(-)$ & $(-)$ & NA & AS, ASP & Type A, AU & $(-)$ \\
\hline 13 & 2 & F & Bilateral & HL & None & $(-)$ & $(-)$ & NA & NA & Type A, AU & $(-)$ \\
\hline 14 & 4 & F & Right & V & None & $(-)$ & $(-)$ & $(+)$ & AS, ASP, CW & NA & $(-)$ \\
\hline
\end{tabular}

${ }^{*} F=$ female $M=$ male; $+V=$ vertigo, $T=$ tinnitus, $D=$ dysequilibrium, $H L=$ hearing loss; ++ Low frequency is measured at 250 to $500 \mathrm{~Hz}$;

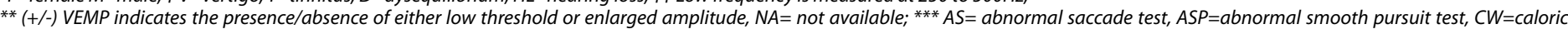
weakness

Table 2. Patients with possible SSCDS on HRCT Scan

\begin{tabular}{|c|c|c|c|c|c|c|c|c|c|c|}
\hline Patient & Age & Sex* & Laterality & $\begin{array}{c}\text { Presenting } \\
\text { Symptomt }\end{array}$ & $\begin{array}{c}\text { Associated } \\
\text { Symptomst }\end{array}$ & $\begin{array}{c}\text { Tullio } \\
\text { Phenomenon }\end{array}$ & $\begin{array}{c}\text { Low frequency } \\
\text { Air-bone gaptt }\end{array}$ & $\begin{array}{c}\text { VEMP } \\
\text { Response** }\end{array}$ & $\begin{array}{c}\text { ENG*** } \\
\text { Tympano- } \\
\text { metry }\end{array}$ \\
\hline 15 & 38 & M & Left & D & T & $(+)$ & $(-)$ & $(+)$ & NA & NA \\
\hline 16 & 31 & M & Left & HL & T & $(-)$ & $(+)$ & NA & NA & NA \\
\hline 17 & 79 & M & Right & D & None & $(+)$ & $(-)$ & $(+)$ & AS, ASP & NA \\
\hline 18 & 34 & M & Bilateral & D & None & $(-)$ & $(+)$ & $(+)$ & CW & NA \\
\hline 19 & 52 & M & Bilateral & T & HL & $(-)$ & $(+)$ & NA & NA & Type A, AU \\
\hline 20 & 63 & F & Bilateral & V & None & $(-)$ & $(-)$ & NA & NA & NA \\
\hline 21 & 30 & F & Left & T & D & $(-)$ & $(-)$ & $(-)$ & AS, ASP & Type A, AU \\
\hline 22 & 36 & F & Right & HL & V & $(-)$ & $(+)$ & $(-)$ & NA & NA \\
\hline 23 & 55 & F & Bilateral & T & D & $(+)$ & $(-)$ & NA & AS, ASP & NA \\
\hline 24 & 6 & M & Bilateral & HL & None & $(-)$ & $(-)$ & NA & NA & Type A, AU \\
\hline
\end{tabular}

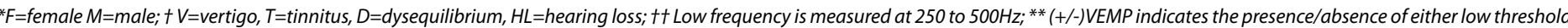

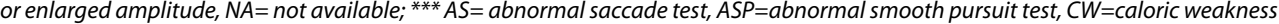

Table 3. Patients without SSCDS as confirmed on HRCT Scan

\begin{tabular}{|c|c|c|c|c|c|c|c|c|c|c|}
\hline Patient & Age & Sex* & Laterality & $\begin{array}{c}\text { Presenting } \\
\text { Symptomt }\end{array}$ & $\begin{array}{c}\text { Associated } \\
\text { Symptomst }\end{array}$ & $\begin{array}{c}\text { Tullio } \\
\text { Phenomenon }\end{array}$ & $\begin{array}{c}\text { Low frequency } \\
\text { Air-bone gaptt }\end{array}$ & $\begin{array}{c}\text { VEMP } \\
\text { Response** }\end{array}$ & $\begin{array}{c}\text { ENG*** } \\
(-)\end{array}$ & $\begin{array}{c}\text { Tympano- } \\
\text { metry }\end{array}$ \\
\hline 25 & 25 & M & Left & V & VA & $\begin{array}{l}\text { Type A, AD } \\
\text { Type B, AS }\end{array}$ \\
\hline 26 & 50 & M & Left & T & T, HL & $(-)$ & $(-)$ & NA & AS, ASP, CW & Type A, AU \\
\hline 27 & 37 & M & Right & T & V & $(-)$ & $(+)$ & NA & NA & NA \\
\hline 28 & 52 & F & Left & T & D & $(-)$ & $(+)$ & $(-)$ & PN, CW & NA \\
\hline 29 & 14 & M & Left & V & None & $(-)$ & $(+)$ & $(-)$ & AS, ASP & NA \\
\hline 30 & 2 & M & Bilateral & HL & None & $(-)$ & $(-)$ & NA & NA & Type A, AU \\
\hline
\end{tabular}

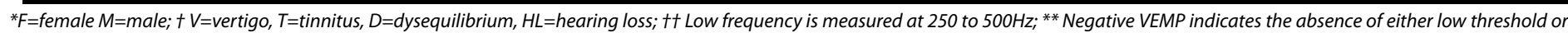
enlarged amplitude, $N A=$ not available; ${ }^{* *} A S=$ abnormal saccade test, $A S P=$ abnormal smooth pursuit test, $C W=$ caloric weakness, $P N=$ positional nystagmus 


\section{Table 4. Summary of Results}

\begin{tabular}{|c|c|c|c|c|}
\hline & $\begin{array}{c}\text { Common } \\
\text { Presenting } \\
\text { Symptoms }\end{array}$ & $\begin{array}{c}\text { Tullio } \\
\text { Phenomenon }\end{array}$ & $\begin{array}{c}\text { Low frequency } \\
\text { Air-bone gap* }\end{array}$ & $\begin{array}{c}\text { VEMP } \\
\text { Responset }\end{array}$ \\
\hline $\begin{array}{c}\text { SSCDS confirmed by } \\
\text { HRCT scan ( } n=14 \\
\text { patients) }\end{array}$ & $\begin{array}{c}\text { Vertigo }(9 \text { out of } 14 \\
\text { patients }=64.3 \%)\end{array}$ & $\begin{array}{c}50 \% \\
\text { (7 out of } 14 \\
\text { patients) }\end{array}$ & $\begin{array}{c}21.4 \% \\
\text { (3 out of 14 patients) }\end{array}$ & $\begin{array}{c}66.7 \% \\
\text { (4 out of 6 patients } \\
\text { who had VEMP) }\end{array}$ \\
\hline $\begin{array}{c}\text { Possible SSCDS on } \\
\text { chart report ( } n=10 \\
\text { patients) }\end{array}$ & $\begin{array}{c}\text { Dysequilibrium } \\
\text { (3 out of 10 patients } \\
=30 \%) \\
\text { Hearing Loss } \\
\text { (3 out of 10 patients } \\
=30 \%) \\
\text { Tinnitus } \\
\text { (3 out of 10 patients } \\
=30 \%)\end{array}$ & $\begin{array}{c}30 \% \\
\text { (3 out of } 10 \\
\text { patients) }\end{array}$ & $\begin{array}{c}40 \% \\
\text { (4 out of } 10 \\
\text { patients) }\end{array}$ & $\begin{array}{c}60 \% \\
\text { (3 out of } 5 \text { patients } \\
\text { who had VEMP) }\end{array}$ \\
\hline $\begin{array}{c}\text { Without SSCDS } \\
\text { based on HRCT scan } \\
(n=6 \text { patients) }\end{array}$ & $\begin{array}{c}\text { Tinnitus } \\
\text { (3 out of } 6 \text { patients } \\
=50 \%)\end{array}$ & $0 \%$ & (4 out of 6 patients) & \\
\hline
\end{tabular}

* Low frequency is measured at 250 to $500 \mathrm{~Hz}$; + VEMP response indicates the presence of either low threshold or enlarged amplitude.

\section{Table 5. VEMP Threshold and Amplitude}

\begin{tabular}{|c|c|c|c|c|c|}
\hline Patient & Laterality & $\begin{array}{c}\text { Ipsilateral } \\
\text { VEMP } \\
\text { Amplitude, AD }\end{array}$ & $\begin{array}{c}\text { Ipsilateral } \\
\text { VEMP Threshold, } \\
\text { AD }\end{array}$ & $\begin{array}{c}\text { Contralateral } \\
\text { VEMP } \\
\text { Amplitude, AS }\end{array}$ & $\begin{array}{c}\text { Contralateral } \\
\text { VEMP Threshold, } \\
\text { AS }\end{array}$ \\
\hline 1 & Right & $\begin{array}{c}\text { No repeatable } \\
\text { wave peaks }\end{array}$ & None & $23.56 \mathrm{uV}$ & $105 \mathrm{~dB}$ \\
\hline 3 & Bilatera* $^{*}$ & $19.49 \mathrm{uV}$ & $88 \mathrm{~dB}$ & $39.68 \mathrm{uV}$ & $85 \mathrm{~dB}$ \\
\hline 5 & Bilatera* $^{*}$ & $29.95 \mathrm{uV}$ & $85 \mathrm{~dB}$ & $19.58 \mathrm{uV}$ & $85 \mathrm{~dB}$ \\
\hline 10 & Right & $25.03 \mathrm{uV}$ & $85 \mathrm{~dB}$ & $40.42 \mathrm{uV}$ & $85 \mathrm{~dB}$ \\
\hline 11 & Left & $62.04 \mathrm{uV}$ & $95 \mathrm{~dB}$ & $91.08 \mathrm{uV}$ & $85 \mathrm{~dB}$ \\
\hline 14 & Right & $96.53 \mathrm{uV}$ & $75 \mathrm{~dB}$ & $47.59 \mathrm{uV}$ & $105 \mathrm{~dB}$ \\
\hline 15 & Left & $38.24 \mathrm{uV}$ & $95 \mathrm{~dB}$ & $47.19 \mathrm{uV}$ & $95 \mathrm{~dB}$ \\
\hline 17 & Right & $\begin{array}{c}\text { No wavepeaks } \\
\text { were noted at }\end{array}$ & None & $\begin{array}{c}\text { No repeatable } \\
\text { wave peaks }\end{array}$ & None \\
\hline 18 & Bilatera* & $102.8 \mathrm{uV}$ & $85 \mathrm{~dB}$ & $65.59 \mathrm{uV}$ & $85 \mathrm{~dB}$ \\
\hline 21 & Left & $125 \mathrm{uV}$ & $95 \mathrm{~dB}$ & $98.03 \mathrm{uV}$ & $105 \mathrm{~dB}$ \\
\hline 22 & Right & $70.97 \mathrm{uV}$ & $95 \mathrm{~dB}$ & $75.48 \mathrm{uV}$ & $95 \mathrm{~dB}$ \\
\hline 25 & Left & $83.81 \mathrm{uV}$ & $95 \mathrm{~dB}$ & $51.20 \mathrm{uV}$ & $95 \mathrm{~dB}$ \\
\hline 28 & Left & $36.38 \mathrm{uV}$ & $95 \mathrm{~dB}$ & $27.52 \mathrm{uV}$ & $95 \mathrm{~dB}$ \\
\hline 29 & Left & $48.34 \mathrm{uV}$ & $95 \mathrm{~dB}$ & $46.37 \mathrm{uV}$ & $95 \mathrm{~dB}$ \\
\hline
\end{tabular}

*Bilateral involvement of the SSC with one side being more symptomatic. Patient 3:lowered threshold/enlarged amplitude on the left >right; Patient 5:enlarged amplitude on the right $>$ left; Patient 18:enlarged amplitude on the right $>$ left out $(\leq 0.1 \mathrm{~mm})$ semicircular canal in patients with this disorder (Figures 1.1, 1.2). In a study of cadaveric temporal bones of adults and children, a dehiscence of the bone overlying the superior canal was found in approximately $0.4-0.5 \%$ of temporal bone specimens. ${ }^{16}$ This has been observed even on temporal bones of infants which may indicate a possible developmental etiology.

It used to be that only HRCT scans using thin cuts with $0.5-0.8 \mathrm{~mm}$ collimation in coronal, axial and saggital reconstructions had proven value in diagnosing SSCDS. Recently however, $\mathrm{T} 2$ weighted images on MRI have a reported sensitivity of $96 \%$ and specificity of $98 \%$ versus HRCT scans which have a sensitivity and specificity of $100 \%$ and $96 \%$ respectively. ${ }^{17-18}$ Knowledge of the appearance of the dehiscence on MRI will help in identifying this disorder (Figure 1.3). This may be helpful in detecting the presence of SSCDS in patients whose clinical manifestations are suggestive of this disorder but whose symptoms also point to other possible disease entities that are diagnosed by MRI so that a single imaging modality may help differentiate one from the other.

VEMP is an otolith-mediated, short-latency reflex that is recorded from averaged sternocleidomastoid electromyography in response to intense auditory clicks delivered via headphones. ${ }^{19}$ Studies have shown lower VEMP thresholds on ears affected with SSCDS as compared to the normal ears. This test is still not widely available locally so not all patients benefited from testing. Six patients with confirmed SSCDS who underwent VEMP testing were noted to have a threshold of $85 \mathrm{~dB}$ with four patients demonstrating either a lower threshold or enlarged amplitudes of the involved side compared to the contralateral side. Two patients were noted to have absent repeatable wave peaks (Table 5). The mechanism responsible for the lowered VEMP threshold in these patients is likely to be related to the lowered impedance for transmission of sound and pressure stimuli created by the third mobile window. ${ }^{13}$

Other ancillary tests were done to help establish the diagnosis of SSCDS. ENG helped in monitoring the eye movements brought about by dizziness or unsteadiness. Tympanometry, on the other hand, helped document the absence of middle ear disease especially in cases where low frequency air bone gap was evident in order to rule out the presence of middle ear disease.

Management of SSCDS is primarily conservative, with the use of vestibular suppressants, diuretics, low-salt diet and refraining from carrying heavy objects. However, patients who present with debilitating symptoms affecting their everyday living may have the option to undergo surgical repair. Resurfacing and plugging of the superior semicircular canal have been described, most commonly via a middle cranial fossa approach. ${ }^{20}$ In this report, the only patient surgically 


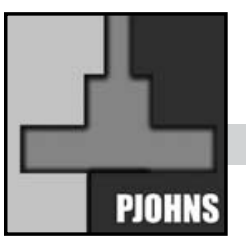

managed for intractable SSCDS underwent combined resurfacing and plugging of the superior semicircular canal. Intraoperative evidence of the dehiscent superior semicircular canal was noted and plugged using bone pate as well as resurfaced with temporalis fascia and a very thin bony plate from craniotomy outer cortex (Figure 2). An improvement on her audiogram after the surgery was noted with eventual closure of the air bone gap (Figures 3.1, 3.2).

This series of cases shows that SSCDS is not exclusive to adults. Children may also have SSCDS although an initial finding of hearing loss is more common compared to vertigo in adults. Minor acknowledged that he has only seen two pediatric patients both in their teenage years since his initial report on this syndrome (personal communication with the co-author CMC, August 2008). Close follow-up of these children with SSCDS is warranted given the significant length of time that the clinical manifestations of SSCDS might be observed. This series also provides a picture of how patients with SCCDS may vary with regards to their clinical presentation as well as with the results of the diagnostic tests. The diagnosis of SSCDS cannot be accepted or excluded by the mere presence or absence of a symptom, sign or audiologic result. On the other hand, the diagnosis based on HRCT scan is standard. The important thing is to know when to consider SSCDS as the patient presents in the clinic and prompt one to ask for a HRCT scan or MRI. Thus, good clinical correlation and increased awareness of the disease will help us in the proper management of SSCDS patients.
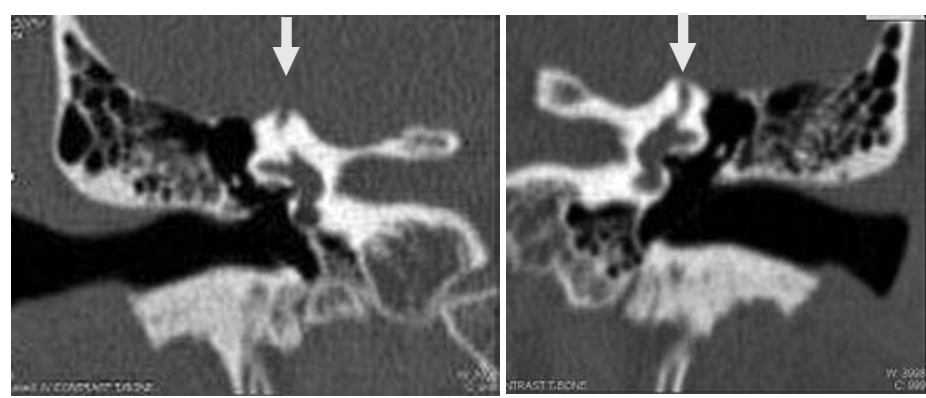

Figure 1.1. Arrow indicates a right superior Figure 1.2. Arrow indicates a left superio semicircular canal dehiscence as shown by absence semicircular canal dehiscence as shown by of bone by HRCT scan (Patient 9).

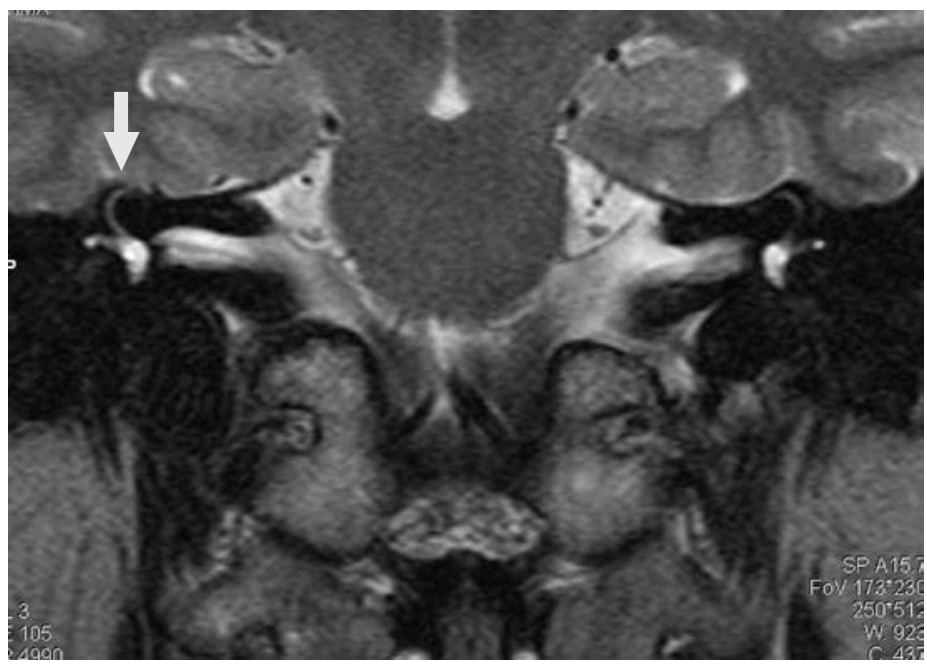

Figure 1.3. Arrow indicates a right superior semicircular canal dehiscence on MRI as shown by a bone defect (Patient 7).

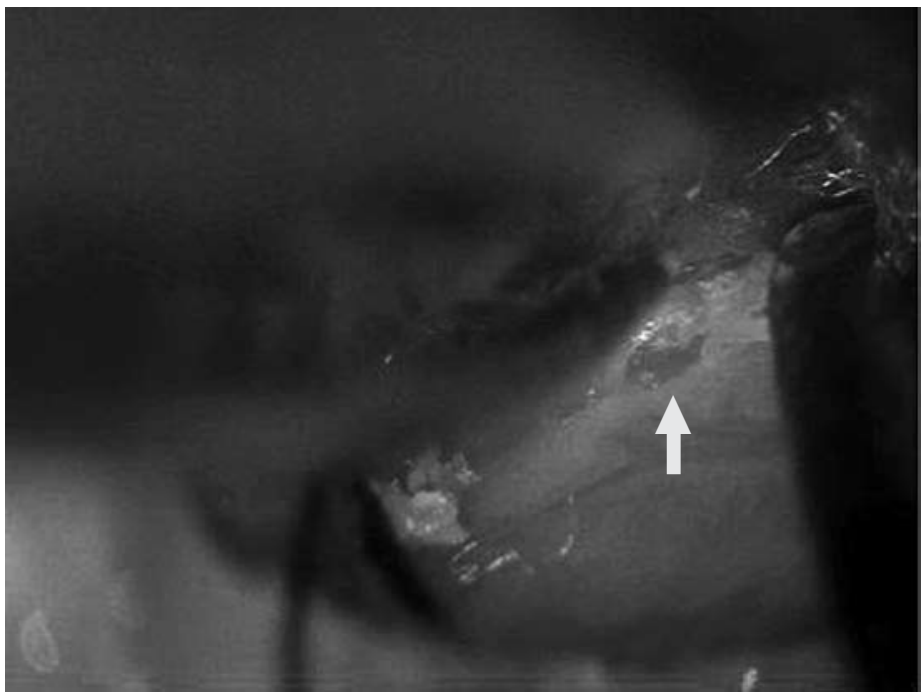

Figure 2. Intraoperative photograph of Patient 1 (case report 1) showing the dehiscent superio semicircular canal with appearance of grayish membranous labyrinth (arrow) against the white solid bone in the rest of the arcuate eminence of the superior canal. 


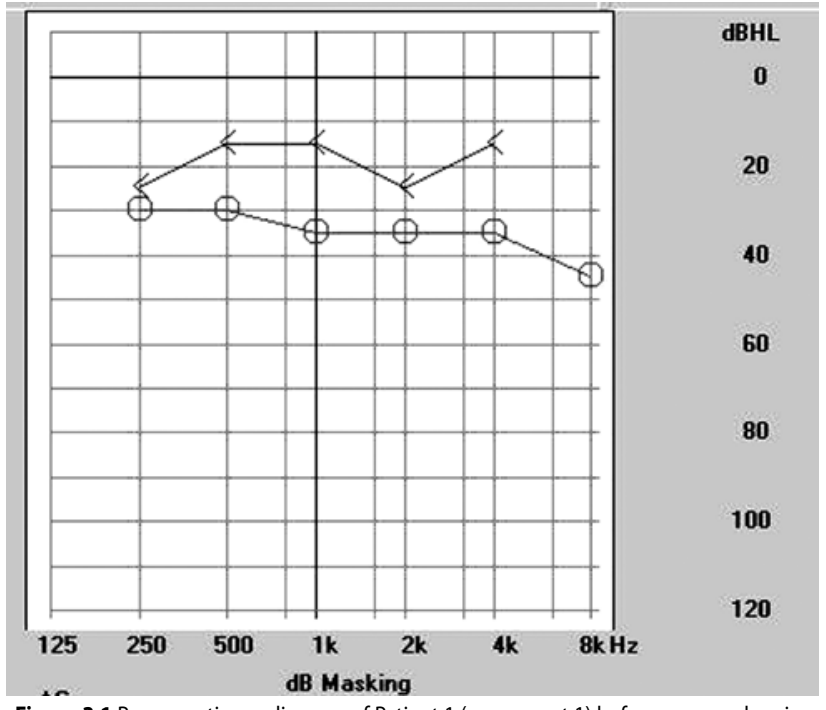

Figure 3.1 Pre-operative audiogram of Patient 1 (case report 1) before surgery showing low frequency air-bone gap.

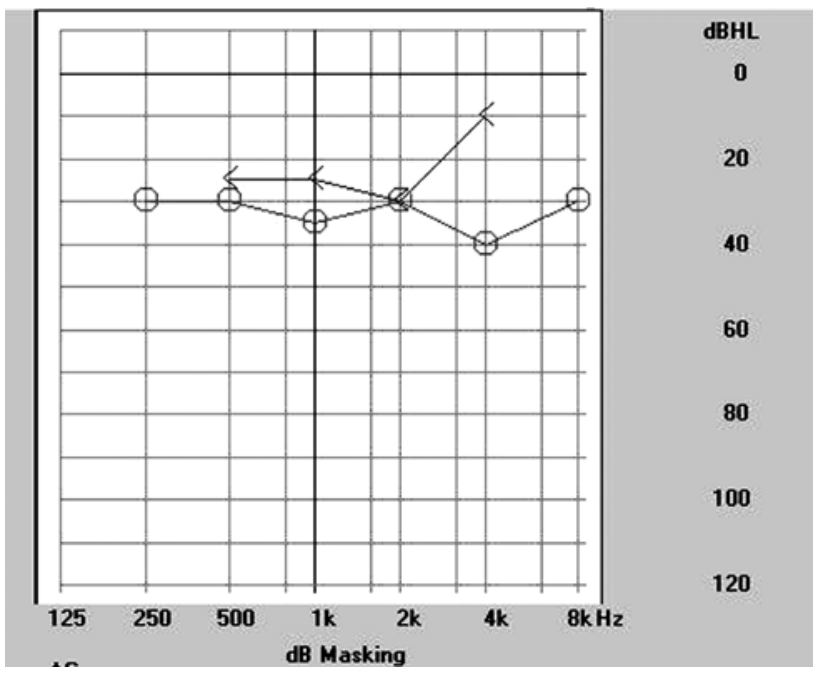

Figure 3.2 Post-operative audiogram of Patient 1 (case report 1) after surgery showing an improvement of low frequency air-bone gap.

\section{REFERENCES}

1. Minor LB, Solomon D, Zinreich JS, Zee DS. Sound-and/or pressure-induced vertigo due to bone dehiscence of the superior semicircular canal. Arch Otolaryngol Head Neck Surg 1998; 124: 249258.

2. Smullen JL, Andrist EC, Gianoli GJ. Superior semicircular canal: a new cause of vertigo. J La State Med Soc 1999; 151(8):397-400.

3. Ong ET, Chiong CM. Superior semicircular canal dehiscence syndrome. Philipp J Otolaryngol Head Neck Surg 2004; 19(3-4): 222-226.

4. Modugno GC, Brandolini C, Savastio G, Ceroni AR, Pirodda A. Superior semicircular canal dehiscence: a series of 13 cases. ORL J Otorhinolaryngol Relat Spec 2005; 67:180-184.

5. Kwee SL. The occurrence of the Tullio phenomenon in congenitally deaf children. J Laryngol Otol 1976; 90:501-507.

6. Halmagyi GM, Aw ST, McGarvie LA et al. Superior semicircular canal dehiscence simulating otosclerosis. J Laryngol Otol 2003; 117:553-7.

7. Fox EJ, Balkany TJ, Arenberg IK. The Tullio phenomenon and perilymph fistula. Otolaryngol Head Neck Surg 1988; 98:88-89.

8. Rottach KG, von Maydell RD, Discenna AO, Zivotofsky AZ, Averbuch-Heller L, Leigh RJ. Quantitative measurements of eye movements in a patient with Tullio phenomenon. J Vestib Res. 1996; 6:255-259.

9. Nields JA. Kveton JF. Tullio phenomenon and seronegative Lyme borreliosis. Lancet 1991; 338:128-129.

10. Ishizaki H. Pyykko I, Aalto H, Starck J. Tullio phenomenon and postural stability: experimental study in normal subjects and patients with vertigo. Ann Otol Rhinol Laryngol 1991; 100:976983.

11. Calaquian $\mathrm{CM}$, Chiong $\mathrm{CM}$, editors. Superior semicircular canal dehiscence presenting as sudden hearing loss. Proceedings of the $7^{\text {th }}$ Hearing International Annual Meeting; 2006 Nov 28- Dec 1; Manila, Philippines.

12. Mikulec AA, McKenna MJ, Ramsey MJ, Rosowski JJ, Hermann BS, Rauch SD, Curtin HD, Mechant SN. Superior semicircular canal dehiscence presenting as conductive hearing loss without vertigo. Otol Neurotol 2004; 25:121-129.

13. Minor LB. Clinical manifestations of superior semicircular canal dehiscence. Laryngoscope 2005 115:1717-1727.

14. Tullio P. Das Ohr und die Entstehung der Sprache und Schrift. Berlin: Urban and Schwarzenberg, 1929. Cited by Ostrowski et al. Otol Neurotol 22:61-65.

15. Kacker S, Hinchcliffe R. Unusual Tullio phenomenon. J Laryngol Otol 1970; 84:155-166.

16. Rottach K, von Maydell R, DiScenna A, et al. Quantitative measurements of eye movements in a patient with Tullio phenomenon. J Vestibular Res 1996; 6:255-259.

17. Krombach GA, Schmitz-Rode T, Haage P, DiMartino K, Prescher A, Kinzel S, Gunther RE. Semicircular canal dehiscence: comparison of T-2 weighted turbo spin-echo MRI and CT. Neuroradiology 2004.46:326-331.

18. Belden CJ, Weg N, Minor LB, Zinreich SJ. CT evaluation of bone dehiscence of the superior semicircular canals a cause of sound- and/or pressure induced vertigo. Radiology 2003; 226:337-343.

19. Welgampola MS, Colebatch JG. Characteristics and clinical applications of vestibular-evoked myogenic potentials. Neurology 2005; 64(10):1682-1688.

20. Minor LB: Superior canal dehiscence syndrome. Am J Otolaryngol 2000; 21:9-19. 